\title{
A narrative review of research advances in hypoxic pulmonary hypertension
}

\author{
Tianci Chai", Chen Qiu", Zhihong Xian, Yongzhen Lu, Yuwei Zeng, Jie Li
}

Key Laboratory of Shenzhen Respiratory Disease, Shenzhen Institute of Respiratory Disease, Shenzhen People's Hospital (The First Affiliated Hospital of Southern University of Science and Technology, The Second Clinical Medical College of Jinan University), Shenzhen, China

Contributions: (I) Conception and design: J Li, T Chai, C Qiu; (II) Administrative support: J Li, T Chai, C Qiu; (III) Provision of study materials or patients: All authors; (IV) Collection and assembly of data: All authors; (V) Data analysis and interpretation: J Li, C Qiu, T Chai; (VI) Manuscript writing: All authors; (VII) Final approval of manuscript: All authors.

"These authors contributed equally to this work.

Correspondence to: Jie Li. Key Laboratory of Shenzhen Respiratory Disease, Shenzhen Institute of Respiratory Disease, Shenzhen People's Hospital (The First Affiliated Hospital of Southern University of Science and Technology, The Second Clinical Medical College of Jinan University), Shenzhen 518020, China. Email: ljszry2018@126.com.

Background and Objective: Hypoxic pulmonary hypertension (HPH) is a pathological syndrome characterized by pulmonary vasoconstriction and pulmonary vascular remodeling caused by hypoxia, which eventually leads to right heart failure or death. There are 2 stages of onset of HPH: hypoxic pulmonary vasoconstriction (HPV) and hypoxic pulmonary vascular remodeling (HPVR). It is an important pathophysiological link in the pathogenesis of chronic obstructive pulmonary disease (COPD) and chronic mountain sickness (CMS), and its severity is closely related to the course and prognosis of COPD and CMS. However, there is a lack of systematic review on the diagnosis, pathogenesis and treatment of HPH. The objective of this paper is to review the diagnosis, pathogenesis, treatment of $\mathrm{HPH}$.

Methods: In this paper, the method of literature review is adopted to obtain the information about HPH. Based on the literature, comprehensive and systematic review is made. The diagnosis, pathogenesis, treatment of $\mathrm{HPH}$ are summarized.

Key Content and Findings: Right heart catheterization is the gold standard for diagnosing HPH. Hypoxia-inducible factor, oxidative stress, metal metabolism, ion channel, inflammatory cytokines, cell apoptosis and vascular factors are the main pathogenesis of HPH. The treatment of HPH includes longterm oxygen therapy, statins, prostaglandins, phosphodiesterase inhibitor and ET receptor antagonists.

Conclusions: Although great progress has been made in the pathophysiology and molecular biology of $\mathrm{HPH}$, it is still unclear which factors play a leading role in the pathogenesis of HPH, and no breakthrough has been made in the treatment of HPH. It is believed that the specific mechanism will be revealed as the research continues, and earlier diagnosis and the development of more effective targeted drugs will be the focus of future research.

Keywords: Hypoxic pulmonary hypertension (HPH); hypoxic pulmonary vasoconstriction (HPV); hypoxic pulmonary vascular remodeling (HPVR); hypoxia-inducible factor (HIF)

Submitted Dec 10, 2021. Accepted for publication Feb 18, 2022.

doi: $10.21037 /$ atm-22-259

View this article at: https://dx.doi.org/10.21037/atm-22-259 


\section{Introduction}

Hypoxic pulmonary hypertension $(\mathrm{HPH})$ is a kind of vascular disease caused by pulmonary hypoxia, characterized by pulmonary vascular remodeling and increased resistance, endothelial dysfunction, medium membrane smooth muscle cell proliferation, and extracellular matrix deposition (1). There are 2 stages of onset of HPH: hypoxic pulmonary vasoconstriction (HPV) and hypoxic pulmonary vascular remodeling (HPVR). It is an important pathophysiological link in the pathogenesis of chronic obstructive pulmonary disease (COPD) and chronic mountain sickness (CMS), and its severity is closely related to the course and prognosis of COPD and CMS $(2,3)$. Due to the complexity of its pathogenesis and the late appearance of symptoms in the disease development, the patient's condition has usually progressed to the middle and late stage when clinical treatment is carried out, by which time, the condition cannot be greatly improved with treatment. Moreover, the currently available drugs cannot prevent or reverse the progression of the disease, so there is an urgent need to develop new diagnostic and therapeutic methods. Although the diagnosis and management of $\mathrm{HPH}$ have been reviewed in a literature, the included literature does not represent the latest research progress in this field due to its age, and the pathogenesis and clinical treatment effect of HPH have not been systematically reviewed. Therefore, this study aimed to review the diagnosis, pathogenesis, and treatment of $\mathrm{HPH}$, to provide a reference for the development of new diagnostic and therapeutic methods. We present the following article in accordance with the Narrative Review reporting checklist (available at https://atm.amegroups.com/article/ view/10.21037/atm-22-259/rc).

\section{Methods}

Information used to write this paper was collected from the sources listed in Table 1.

\section{The diagnosis of HPH}

According to the diagnostic criteria of the World Health Organization (WHO), the mean pulmonary artery pressure (mPAP) measured by right heart catheterization is used as the diagnostic gold index for $\mathrm{HPH}$, and $\mathrm{mPAP} \geq 25 \mathrm{mmHg}$ at resting state at sea level is considered as the reference level (4). The Gold standard of WHO means it can be used as a diagnostic criterion for pulmonary hypertension, and other adjunct tests are used to screen high-risk populations or for patients who cannot undergo right heart catheterization. Supplementary tests can often provide clues to pulmonary hypertension when the patient cannot tolerate right heart catheterization, and non-invasive tests such as echocardiography can also provide a diagnosis. As the clinical manifestations of $\mathrm{HPH}$ are often masked by the primary disease and are atypical,

Table 1 The search strategy summary

\begin{tabular}{|c|c|}
\hline Items & Specification \\
\hline Databases and other sources searched & $\begin{array}{l}\text { PubMed, Index to Chiropractic Index to Chiropractic, MANTIS, } \\
\text { ERIC (Educational Resources Information Center), AMED (Allied and } \\
\text { Complementary Medicine Database), CINAHL (Cumulative Index to } \\
\text { Nursing and Allied Health Literature), EMBASE/Excerpta Medica, } \\
\text { Cochrane Database of Systematic Reviews }\end{array}$ \\
\hline Timeframe & $\begin{array}{l}\text { Interesting topic: 1/6/2020; literature search: 1/9/2020; literature } \\
\text { screening: 2021; paper writing: 2021; paper submissions: } 2022\end{array}$ \\
\hline Any additional considerations, if applicable & None \\
\hline
\end{tabular}




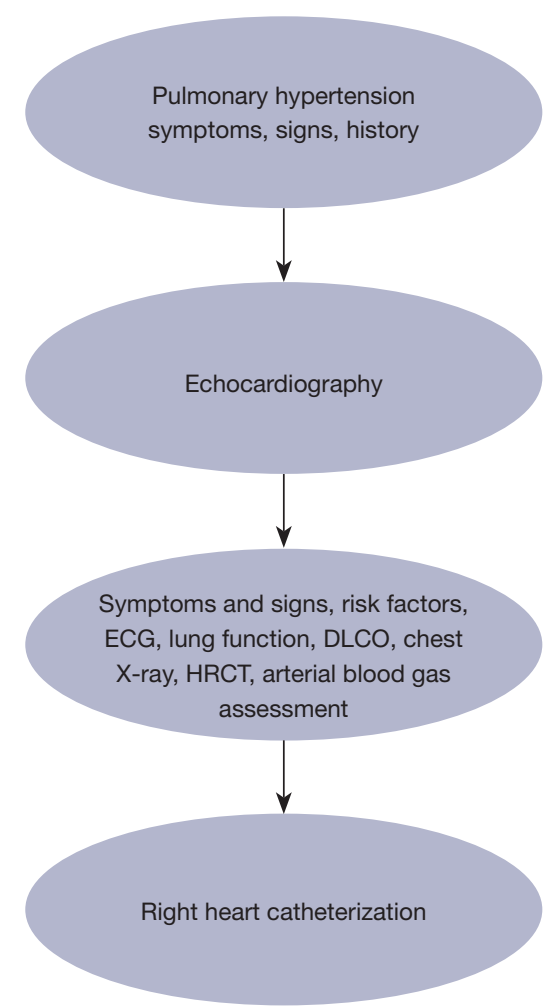

Figure 1 The diagnosis of HPH. ECG, electrocardiogram; DLCO, carbon monoxide dispersion; HRCT, high-resolution computed tomography; HPH, hypoxic pulmonary hypertension.

patients with high-risk factors should be alert to the possibility of pulmonary hypertension. As shown in Figure 1, we have organized the diagnostic methods of HPH.

\section{Signs and symptoms}

The symptoms of HPH include chest tightness, shortness of breath, chest pain, fatigue, syncope, and edema, and some patients experience dry cough and hemoptysis $(5,6)$. The patient's physical signs can be related to right heart insufficiency and hypertrophy, including lifting pulse at the left sternal margin, P2 hyperactivity, third heart sound in the right ventricular auscultation area, total systolic murmurs in the tricuspid valve area and diastolic murmurs in the pulmonary valve area, jugular vein filling or even dilation, limb edema, hepatosplenomegaly, and so on (7-10).

\section{Right beart catheterization}

Right heart catheterization is the gold standard for the diagnosis and evaluation of pulmonary hypertension. It can provide central venous pressure, right atrium pressure, pulmonary artery pressure, pulmonary capillary wedge pressure, cardiac output, and blood oxygen saturation, and determine the degree of hemodynamic impairment $(11,12)$. It can also be used to conduct an acute vasodilation test. Reexamination of right heart catheterization can be helpful in evaluating outcomes in patients who have already been treated.

\section{Electrocardiogram}

As a simple diagnostic method, although electrocardiogram (ECG) cannot exclude the existence of pulmonary hypertension, it can still provide a valuable diagnostic basis. Patients with pulmonary hypertension may have pulmonary type-P wave, right axis deviation, right ventricular hypertrophy, right bundle branch block, QTc prolongation, and so on (13-15).

\section{Computed tomography (CT)}

CT can not only measure the diameter of aorta, diameter ratio of pulmonary artery to ascending aorta, evaluate the vascular condition, right heart shape and size, atrial and ventricular wall thickness, but also contribute to the differential diagnosis of primary diseases, such as interstitial lesions, pulmonary space occupation, pulmonary artery space occupation, and so on $(16,17)$.

\section{Magnetic resonance imaging (MRI)}

MRI can clearly image the right ventricle and pulmonary artery, and can also generate dynamic images to measure blood flow $(18,19)$. It is an important non-invasive examination method to evaluate the shape and function of the right heart in patients with pulmonary hypertension $(20,21)$.

\section{Blood tests}

Arterial blood gas should be monitored in patients with $\mathrm{HPH}$, especially in those with primary COPD. The hemoglobin can be increased due to hypoxia compensation, and brain natriuretic peptide (BNP) and N-terminal type-B natriuretic peptide precursor (NT-proBNP) are often elevated to varying degrees, which are positively correlated with the severity of disease and the prognosis of patients (22-24). New diagnostic markers, such as asymmetric 
dimethylarginine (ADMA), can evaluate the dysfunction of endothelial cells. The growth differentiation factor-15 (GDF-15), galectin-3, and macrophage migration inhibitory factor (MIF) are also under study (25-28).

\section{The pathogenesis of HPH}

\section{Hypoxia-inducible factor (HIF)}

HIF is an oxygen-sensitive transcription factor, which is the core of metabolic response to hypoxic stimulation. All of HIF-1, HIF-2, and HIF-3 are heterodimers composed of oxygen-sensitive $\alpha$ subunit (HIF-1 $\alpha$, HIF-2 $\alpha$, HIF-3 $\alpha$ ) and oxygen-insensitive $\beta$ subunit. In hypoxia, proteasome degradation of HIF-1/HIF-2 subunit is inhibited, resulting in nuclear translocation and binding to HIF-1 subunit (29). The heterodimer transcription factor binds to the hypoxic response element and results in the activation of more than 100 genes downstream to participate in the cellular adaptive response $(30,31)$. In a low oxygen environment, HIF inhibits glucose oxidation and promotes glycolysis by increasing the content of pyruvate dehydrogenase kinase $(32,33)$. As an acute response, this adaptive mechanism has short-term protection; however, chronic hypoxic stress and maladjustment of these protective mechanisms can induce $\mathrm{HPH}$.

\section{Oxidative stress}

Reactive oxygen species (ROS) is considered to be an important signal molecule in oxidative metabolism, and its increase or decrease will eventually lead to pulmonary vasodilation or contraction (34). Complexes I, II, and III in the mitochondrial electron transport chain (ETC) are the main sites of ROS generation. Inhibition of pyruvate generation in aerobic respiration can reduce tricarboxylic acid (TCA) cycle and mitochondrial ROS generation in ETC. Therefore, ROS generation is reduced during hypoxia, leading to HIF activation and inhibition of the Kv1.5 channel. This process ultimately induces cell depolarization, and more calcium ions enter cytoplasm through L-type voltage-gated calcium channel, which leads to pulmonary vasoconstriction and promotes $\mathrm{HPH}$ progression (35-38).

\section{Metal metabolism}

Bioactive metals are an important part of enzymes, and as necessary cofactors of metabolic reaction, their metabolic disorder has an important relationship with HPH. Some researchers have observed iron deficiency in HPH rats and believe that iron deficiency can be considered a mechanism to inhibit iron ion clusters, which is caused by substrate deprivation (39). Iron-sulfur clusters assembly proteins 1 and 2 (ISCu1/2) are responsible for assembling iron-sulfur clusters, and are necessary prosthetic groups of TCA cycle and mitochondrial complexes I, II, and III in ETC. It is also a direct inhibitory target of hypoxia-induced MIR-210 (40). In hypoxia, HIF induces erythropoietin expression and red blood cell production, thereby consuming iron through hemoglobin synthesis $(41,42)$. Beyond a certain threshold, MIR-210 can reduce the expression of ISCu1/2, resulting in a decrease in the content of iron-sulfur clusters, ETC activity, and ROS production, leading to insufficient $\mathrm{H}_{2} \mathrm{O}_{2}$ reaching the plasma membrane $(43,44)$. This process can shrink primary human pulmonary artery smooth muscle cells (PASMCs) and weaken Fe-S-dependent mitochondrial respiration (45). It promotes glycolysis in pulmonary arterial endothelial cell. In the acute phase, this mechanism facilitates the cellular stress response, while in the chronic state, it leads to mitochondrial metabolic disorder and reprogramming, promoting the emergence and development of HPH.

The pathogenesis of dysregulation of bioactive zinc ion metabolism in HPH has been established. It was found that Slc39a12 is a major regulator of hypoxia-induced pulmonary vascular remodeling. It encodes zinc transporter 12 (ZIP 12), promoting extracellular absorption and intracellular release of zinc in a variety of cells. It is an important regulator of zinc homeostasis. Study has shown that under hypoxia induction, ZIP 12 expression in pulmonary artery endothelial cells, smooth muscle cells, and stromal cells increases, resulting in increased expression of HIF $1 / 2$ and promoting the proliferation of these cells, indicating that imbalance of zinc homeostasis is related to the development of HPH (46).

\section{Ion channel}

The initiating link and the main pathological process of $\mathrm{HPH}$ is HPV. In the later stage of $\mathrm{HPH}$, pulmonary vascular remodeling is the main pathophysiological change, and ion channels are involved in the contraction and proliferation of pulmonary vascular smooth muscle cells. According to biophysical and pharmacological characteristics, there are 3 kinds of potassium channels in pulmonary vascular smooth muscle: delayed rectifier 
potassium channels $\left(\mathrm{K}_{\mathrm{DR}}\right)$, calcium ion activated potassium channel $\left(\mathrm{K}_{\mathrm{Ca}}\right)$, and adenosine triphosphate (ATP) sensitive potassium channel $\left(\mathrm{K}_{\mathrm{ATP}}\right)$ (47). They play an important role in the vasomotor response of pulmonary vascular smooth muscle, such as determining resting membrane potential, regulating vascular tension, and influencing pulmonary artery smooth muscle proliferation. Intracellular potassium ion flows through 3 potassium channels, causing membrane depolarization, among which $\mathrm{K}_{\mathrm{DR}}$ is the main potassium channel determining the resting membrane potential of PASMCs. Acute hypoxia inhibits $\mathrm{K}_{\mathrm{DR}}$ function, leading to a decrease in $\mathrm{K}^{+}$outflow and membrane potential, inducing membrane depolarization, thus initiating calcium channel opening to allow extracellular calcium to enter the cell. Increased calcium level promotes the release of histamine, angiotensin II, and other neurotransmitters, resulting in HPV (48). The distribution of $\mathrm{K}_{\mathrm{Ca}}$ is wide in PASMCs and it is directly involved in regulation of vascular tone. The opening of this channel can polarize the membrane potential and cause vascular dilation. When vascular smooth muscle cells depolarize and $\mathrm{Ca}^{2+}$ enters cells, $\mathrm{K}_{\mathrm{Ca}}$ plays a negative feedback regulation role (49). Under normal circumstances, $\mathrm{K}_{\mathrm{ATP}}$ is in the closed state. In acute severe hypoxia, a large amount of ATP is decomposed or synthesized in the cell, ATP concentration is significantly reduced, and this channel is opened, causing a significant decrease in vascular tension (50).

The increase of intracellular $\mathrm{Ca}^{2+}$ concentration is the key factor leading to the contraction of pulmonary vascular smooth muscle cells. When vascular endothelial cells are stimulated by hypoxia and inflammation, a variety of bioactive substances are released to activate voltagegated calcium channels on the membrane of PASMCs, and $\mathrm{Ca}^{2+}$ influx increases, resulting in increased $\mathrm{Ca}^{2+}$ level in PASMCs, which leads to the occurrence of $\mathrm{HPH}(51,52)$.

\section{Inflammatory cytokines}

In recent years, a large number of studies have shown that lung inflammation plays an important role in the formation and development of HPH. In hypoxia, there may be a positive feedback effect of inflammation-inflammatory mediators-HIF-1-inflammatory mediators-inflammation. It has been shown that HIF-1 not only induces nuclear factor- $\kappa \mathrm{B}(\mathrm{NF}-\kappa \mathrm{B})$ transcription by activating I $\mathrm{B}$ or phosphorylation of $\mathrm{P} 65$ residue Ser276 and enhancing nuclear shift of P65, but also amplifies NF- $\mathrm{kB}$ signaling pathway by increasing toll-like receptors expression (53-55).
Furthermore, it promotes the production of a series of inflammatory mediators, the aggregation of inflammatory cells, and the damage effect on blood vessels. Hypoxia promotes inflammatory cell infiltration and inflammatory factor secretion in lung tissue, which is an important mechanism leading to pulmonary vascular remodeling. Inflammatory cells mainly infiltrate the outer membrane of blood vessels, mainly lymphocytes, especially CD8 ${ }^{+} \mathrm{T}$ cells (56). Chronic vascular inflammation eventually leads to pulmonary vascular remodeling, and its severity is positively correlated with the thickness of the vessel wall. Endothelial cell injury is the key initiating link of vascular inflammatory pathological changes. Under the stimulation of hypoxia, vascular endothelial cells express some special proteins and markers, such as epidermal cell adhesion molecule-1, TGF receptor and E. Selectin, tissue factors, and so on, which initiates the endothelial injury process $(57,58)$. After endothelial injury, the vascular endothelial barrier is damaged, and circulating inflammatory mediators and some growth factors can directly act on the vascular wall. Meanwhile, some external factors, such as vascular endothelial, can accelerate the changes of vascular structure and function when hypoxia occurs, ultimately leading to $\mathrm{HPH}$. The synthesis and expression of cytokines [including monocyte chemokine-1, interleukin-1 (IL-1), IL-6, tumor necrosis factor- $\alpha$ (TNF- $\alpha$ ), platelet-derived growth factor- $\alpha$ (PDGF- $\alpha$ ), C-reactive protein (CRP), and macrophage inflammatory protein, among others] in circulation and lung tissue were shown to be significantly increased in $\mathrm{HPH}$ patients, suggesting that these cytokines and inflammatory mediators may be involved in the formation of HPH and correlated with its severity (59).

\section{Cell apoptosis}

Apoptosis is an important physiological process that causes PASMCs to decrease, thereby reducing pulmonary artery pressure. The proliferation of pulmonary smooth muscle cells and the decrease of apoptosis can increase the thickness of pulmonary arteriole wall, and lead to the constriction of pulmonary artery lumen, the increase of pulmonary vascular resistance, and the increase of pulmonary artery pressure $(60,61)$. In physiological states, proteins that promote and inhibit apoptosis exist in cells to maintain the integrity of mitochondrial membranes by sensing cellular stress and response. The Bcl-2 family proteins control the permeability of mitochondrial membrane through conformational changes under stimulation, which is the key 


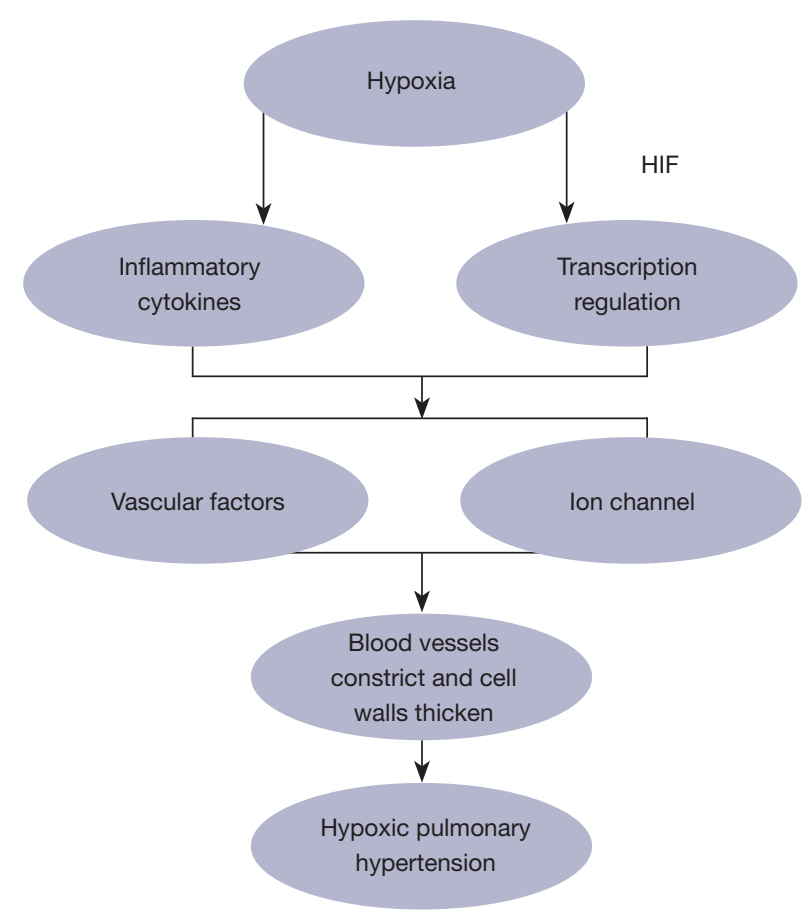

Figure 2 The pathogenesis of HPH. HIF, hypoxia-inducible factor; HPH, hypoxic pulmonary hypertension.

to mitochondrial apoptosis pathway (62). Under chronic hypoxia, the overexpression of $\mathrm{Bcl}-2$ inhibits the expression of Bax, thus increasing the expression of anti-apoptotic and decreasing the expression of pro-apoptotic, leading to the proliferation and remodeling of pulmonary artery smooth muscle (63). In many animal experiments related to HPH, proliferation and apoptosis have been shown to co-exist in the pulmonary vascular cells of HPH rats. The expression of Bcl-2 was significantly increased in the hypoxia group, while the expression of Bax was significantly inhibited, ultimately leading to the proliferation and remodeling of PASMCs $(64,65)$.

\section{Vascular factors}

Endothelial cells with barrier and endocrine functions located on the lumen surface of pulmonary vessels can secrete vascular active factors such as endothelin-1 (ET-1), nitric oxide (NO), thromboxan (TX) A2, 5-hydroxytryptamine (HT), and prostacyclin (PGIs) under induction conditions. They also act on PASMCs by paracrine pathway including endothelin (ET) pathway, NO pathway, and prostacyclin pathway (66). Under hypoxic conditions, it is involved in the regulation of vascular wall tension, smooth muscle cell proliferation and migration, inflammatory response, and thrombosis by blocking the synthesis of induced NO synthase, reducing the bioavailability of NO, up-regulating the expression of ET-1 receptor, reducing the production of $\mathrm{PGl}_{2}$, and increasing the production of TXA2 and 5-HT, which leads to increased pulmonary artery pressure $(67,68)$. As shown in Figure 2, we have organized the pathogenesis of HPH.

\section{The treatment of HPH}

\section{Long-term oxygen therapy}

Besides being a common complication of COPD, HPH is a major factor in the increase of mortality. It is not clear whether long-term oxygen therapy can reduce pulmonary artery pressure in patients with COPD. Long-term lowflow oxygen intake can stabilize mean pulmonary arterial pressure and improves prognosis and survival (69). The ideal treatment for patients with high-altitude pulmonary hypertension (HAPH) is to relocate to low-altitude areas, and oxygen therapy is also an effective treatment for patients who cannot emigrate.

\section{Statins}

Statins are inhibitors of 3-hydroxy 3-methylglutaramidase A reductase, including lovastatin, simvastatin, pravastatin, fluvastatin, and atorvastatin, among others. In addition to the effect of lowering blood lipids, recent studies have found that they still improve endothelial function, and exert effects of anti-inflammatory, antioxidant, and anti-proliferation, thus inducing cell apoptosis (70,71). Simvastatin can reduce pulmonary arterial pressure by inhibiting inflammatory cell invasion in COPD patients with pulmonary arterial hypertension (PAH) (72). Fluvastatin can inhibit the down-regulation of Caveolin-1 expression and prevent the formation of $\mathrm{PAH}$ in rats (73).

\section{Prostaglandins (PGIS)}

PGIS can expand pulmonary circulation and systemic circulation, inhibit platelet aggregation, inhibit smooth muscle cell migration and proliferation, delay pulmonary vascular remodeling, and inhibit ET synthesis and secretion (74-76). At present, the clinical application of PGIS includes intravenous eprostol, subcutaneous treoprost, oral beprost, and inhaled eprost. The combination of these 
drugs with phosphodiesterase type-5 (PDE-5) inhibitors has synergistic effects (77). There are few studies on PGIS analogs, and clinical trials with small samples have suggested that iloprost can improve V/Q ratio and exercise endurance (78).

\section{Phosphodiesterase (PDE) inhibitor}

PDE inactivates the second messenger cGMP of the prostacyclin pathway. Sildenafil is a highly selective PDE-5 inhibitor that prevents the degradation of cGMP and thus increases its diastolic action, as well as reducing pulmonary arterial pressure and improving hemodynamics (79). The therapeutic effect of sildenafil on arterial PAH has been confirmed, but its therapeutic value in HPH is being further studied. Vitulo et al. conducted a multi-center double-blind controlled experiment, in which sildenafil was shown to reduce PVR, improve body mass index, airflow obstruction, dyspnea, and exercise (BODE) index and quality of life in COPD patients, but did not significantly improve blood oxygen partial pressure (80). As for the efficacy of PDE5 inhibitors, Zisman et al. conducted a clinical trial on the efficacy of sildenafil treatment (81). Compared with the control group, the sildenafil group showed no significant improvement in exercise tolerance, but exhibited improved arterial oxygen content, carbon monoxide dispersion (DLCO), shortness of breath, and quality of life. Despite this, there have been trials that have shown that sildenafil improves not only symptoms but also exercise endurance $(82,83)$.

\section{ET receptor antagonists (ERA)}

ET was first discovered in 1988 and is considered the strongest vasoconstriction active substance to date. ET-1 was highly correlated with HPH. Valerio et al. treated 32 patients with pulmonary hypertension and COPD with bosentan or placebo. After 18 months, mPAP, PVR, and 6-minute walking test $(6 \mathrm{MWT})$ improved in the treatment group compared with the placebo group. However, most clinical trials showed that ERA had no significant effect on these patients (84). King et al. conducted a randomized controlled study on the efficacy of bosentan in the treatment of interstitial lung disease (ILD)-associated pulmonary hypertension. Compared with the control group, the quality of life, health, and dyspnea of patients in the bosentan group were not significantly improved (85). Trials have also shown that ambrisentan does not work in these patients, with the use of ambrisentan has even been associated with accelerating disease progression and higher hospitalization rates (86).

\section{Summary}

The disease HPH is a complex pathophysiological process involving many kinds of cells and molecules, and its main inducement is hypoxia. Right heart catheterization is the gold standard for diagnosing HPH, and other methods, especially hematology and noninvasive imaging are also being developed. In the progression of HPH, there are many influencing factors and their interaction forms a complex network relationship. At present, the main treatments are aerobic therapy, statins, prostacyclins, ET antagonists, PDE inhibitors, and so on. With the development and application of new drugs and therapies, the survival rate and quality of life of patients with $\mathrm{HPH}$ have been greatly improved, but the long-term prognosis of HPH is still not optimistic, so earlier diagnosis and the development of more effective targeted drugs will be the focus of future research.

\section{Acknowledgments}

Funding: This work was supported by the Project of Shenzhen Basic Research Plan (No. JCYJ20210324114205014) and the Key Laboratory of Shenzhen Respiratory Disease (No. ZDSYS201504301616234).

\section{Footnote}

Reporting Checklist: The authors have completed the Narrative Review reporting checklist. Available at https:// atm.amegroups.com/article/view/10.21037/atm-22-259/rc

Conflicts of Interest: All authors have completed the ICMJE uniform disclosure form (available at https://atm. amegroups.com/article/view/10.21037/atm-22-259/coif). The authors have no conflicts of interest to declare.

Ethical Statement: The authors are accountable for all aspects of the work in ensuring that questions related to the accuracy or integrity of any part of the work are appropriately investigated and resolved.

Open Access Statement: This is an Open Access article distributed in accordance with the Creative Commons Attribution-NonCommercial-NoDerivs 4.0 International 
License (CC BY-NC-ND 4.0), which permits the noncommercial replication and distribution of the article with the strict proviso that no changes or edits are made and the original work is properly cited (including links to both the formal publication through the relevant DOI and the license). See: https://creativecommons.org/licenses/by-nc-nd/4.0/.

\section{References}

1. Umar S, Cunningham CM, Itoh $\mathrm{Y}$, et al. The $\mathrm{Y}$ Chromosome Plays a Protective Role in Experimental Hypoxic Pulmonary Hypertension. Am J Respir Crit Care Med 2018;197:952-5.

2. Han CF, Li ZY, Li TH. Roles of hypoxia-inducible factor$1 \alpha$ and its target genes in neonatal hypoxic pulmonary hypertension. Eur Rev Med Pharmacol Sci 2017;21:4167-80.

3. Wang L, Jin YZ, Zhao QH, et al. Hemodynamic and gas exchange effects of inhaled iloprost in patients with COPD and pulmonary hypertension. Int J Chron Obstruct Pulmon Dis 2017;12:3353-60.

4. Fang JC, DeMarco T, Givertz MM, et al. World Health Organization Pulmonary Hypertension group 2: pulmonary hypertension due to left heart disease in the adult--a summary statement from the Pulmonary Hypertension Council of the International Society for Heart and Lung Transplantation. J Heart Lung Transplant 2012;31:913-33.

5. Dunlap B, Weyer G. Pulmonary Hypertension: Diagnosis and Treatment. Am Fam Physician 2016;94:463-9.

6. Young JM, Williams DR, Thompson AAR. Thin Air, Thick Vessels: Historical and Current Perspectives on Hypoxic Pulmonary Hypertension. Front Med (Lausanne) 2019;6:93.

7. Marangu D, Jowi C, Aswani J, et al. Prevalence and associated factors of pulmonary hypertension in Kenyan children with adenoid or adenotonsillar hypertrophy. Int J Pediatr Otorhinolaryngol 2014;78:1381-6.

8. Braganza M, Shaw J, Solverson K, et al. A Prospective Evaluation of the Diagnostic Accuracy of the Physical Examination for Pulmonary Hypertension. Chest 2019;155:982-90.

9. Sysol JR, Machado RF. Classification and pathophysiology of pulmonary hypertension. Continuing Cardiology Education, 2018;4:2-12.

10. Hensley MK, Levine A, Gladwin MT, et al. Emerging therapeutics in pulmonary hypertension. Am J Physiol Lung Cell Mol Physiol 2018;314:L769-81.

11. Naeije R, Dedobbeleer C. Pulmonary hypertension and the right ventricle in hypoxia. Exp Physiol 2013;98:1247-56.

12. Quinn DA, Du HK, Thompson BT, et al. Amiloride analogs inhibit chronic hypoxic pulmonary hypertension. Am J Respir Crit Care Med 1998;157:1263-8.

13. Ahmad M, Blomqvist CG, Mullins CB. ECG changes in experimental acute pulmonary hypertension with and without hypoxia. J Electrocardiol 1974;7:109-14.

14. Mangshetty BG, Apuroopa K. Study of clinical profile of chronic obstructive pulmonary disease and evaluation of pulmonary hypertension with ECG and 2D echo findings. Journal of Evolution of Medical and Dental Sciences 2016;5:7331-7.

15. Hoffmann F, Limper U, Zaha VG, et al. Evolution of Pulmonary Hypertension During Severe Sustained Hypoxia. Circulation 2020;141:1504-6.

16. Aluja Jaramillo F, Gutierrez FR, Díaz Telli FG, et al. Approach to Pulmonary Hypertension: From CT to Clinical Diagnosis. Radiographics 2018;38:357-73.

17. Devaraj A, Wells AU, Meister MG, et al. Pulmonary hypertension in patients with bronchiectasis: prognostic significance of CT signs. AJR Am J Roentgenol 2011;196:1300-4.

18. Jaijee S, Quinlan M, Tokarczuk P, et al. Exercise cardiac MRI unmasks right ventricular dysfunction in acute hypoxia and chronic pulmonary arterial hypertension. Am J Physiol Heart Circ Physiol 2018;315:H950-7.

19. Ley S, Kreitner KF, Fink C, et al. Assessment of pulmonary hypertension by CT and MR imaging. Eur Radiol 2004;14:359-68.

20. van de Veerdonk MC, Bogaard HJ, Voelkel NF. The right ventricle and pulmonary hypertension. Heart Fail Rev 2016;21:259-71.

21. Sanz J, Kariisa M, Dellegrottaglie S, et al. Evaluation of pulmonary artery stiffness in pulmonary hypertension with cardiac magnetic resonance. JACC Cardiovasc Imaging 2009;2:286-95.

22. Gordeuk VR, Castro OL, Machado RF. Pathophysiology and treatment of pulmonary hypertension in sickle cell disease. Blood 2016;127:820-8.

23. Clements RT, Vang A, Fernandez-Nicolas A, et al. Treatment of Pulmonary Hypertension With Angiotensin II Receptor Blocker and Neprilysin Inhibitor Sacubitril/ Valsartan. Circ Heart Fail 2019;12:e005819.

24. Rodriguez-Gonzalez M, Benavente-Fernandez I, Castellano-Martinez A, et al. NT-proBNP plasma levels as biomarkers for pulmonary hypertension in healthy infants with respiratory syncytial virus infection. Biomark Med 2019;13:605-18. 
25. Siques P, Brito J, Schwedhelm E, et al. Asymmetric Dimethylarginine at Sea Level Is a Predictive Marker of Hypoxic Pulmonary Arterial Hypertension at High Altitude. Front Physiol 2019;10:651.

26. Nickel N, Jonigk D, Kempf T, et al. GDF-15 is abundantly expressed in plexiform lesions in patients with pulmonary arterial hypertension and affects proliferation and apoptosis of pulmonary endothelial cells. Respir Res 2011;12:62.

27. Barman SA, Li X, Haigh S, et al. Galectin-3 is expressed in vascular smooth muscle cells and promotes pulmonary hypertension through changes in proliferation, apoptosis, and fibrosis. Am J Physiol Lung Cell Mol Physiol 2019;316:L784-97.

28. Zhang Y, Talwar A, Tsang D, et al. Macrophage migration inhibitory factor mediates hypoxia-induced pulmonary hypertension. Mol Med 2012;18:215-23.

29. Pezzuto A, Carico E. Role of HIF-1 in Cancer Progression: Novel Insights. A Review. Curr Mol Med 2018;18:343-51.

30. Slemc L, Kunej T. Transcription factor HIF1A: downstream targets, associated pathways, polymorphic hypoxia response element (HRE) sites, and initiative for standardization of reporting in scientific literature. Tumour Biol 2016;37:14851-61.

31. Rashid I, Nagpure NS, Srivastava P, et al. HREFinder: a tool for quarrying hypoxia-response element in genomic sequences. Int J Curr Microbiol App Sci 2017;6:1580-6.

32. Miska J, Lee-Chang C, Rashidi A, et al. HIF-1 $\alpha$ Is a Metabolic Switch between Glycolytic-Driven Migration and Oxidative Phosphorylation-Driven Immunosuppression of Tregs in Glioblastoma. Cell Rep 2019;27:226-237.e4.

33. Kierans SJ, Taylor CT. Regulation of glycolysis by the hypoxia-inducible factor (HIF): implications for cellular physiology. J Physiol 2021;599:23-37.

34. Prieto-Lloret J, Snetkov VA, Shaifta Y, et al. Role of reactive oxygen species and sulfide-quinone oxoreductase in hydrogen sulfide-induced contraction of rat pulmonary arteries. Am J Physiol Lung Cell Mol Physiol 2018;314:L670-85.

35. He Y, Fang X, Shi J, et al. Apigenin attenuates pulmonary hypertension by inducing mitochondria-dependent apoptosis of PASMCs via inhibiting the hypoxia inducible factor $1 \alpha-K V 1.5$ channel pathway. Chem Biol Interact 2020;317:108942.

36. Guo L, Qiu Z, Wei L, et al. The microRNA-328 regulates hypoxic pulmonary hypertension by targeting at insulin growth factor 1 receptor and L-type calcium channel- $\alpha 1 \mathrm{C}$. Hypertension 2012;59:1006-13.

37. Zhao RZ, Jiang S, Zhang L, et al. Mitochondrial electron transport chain, ROS generation and uncoupling (Review). Int J Mol Med 2019;44:3-15.

38. Madungwe NB, Zilberstein NF, Feng Y, et al. Critical role of mitochondrial ROS is dependent on their site of production on the electron transport chain in ischemic heart. Am J Cardiovasc Dis 2016;6:93-108.

39. Ying L, Xiaohui L, Hong Y. ASSA13-14-3 Iron Metabolism Disorder in Hypopxia-Induced Pulmonary Hypertension Rats. Heart 2013;99:A59.

40. Chan SY, Zhang YY, Hemann C, et al. MicroRNA-210 controls mitochondrial metabolism during hypoxia by repressing the iron-sulfur cluster assembly proteins ISCU1/2. Cell Metab 2009;10:273-84.

41. Hsieh MM, Linde NS, Wynter A, et al. HIF prolyl hydroxylase inhibition results in endogenous erythropoietin induction, erythrocytosis, and modest fetal hemoglobin expression in rhesus macaques. Blood 2007;110:2140-7.

42. Rankin EB, Wu C, Khatri R, et al. The HIF signaling pathway in osteoblasts directly modulates erythropoiesis through the production of EPO. Cell 2012;149:63-74.

43. He M, Lu Y, Xu S, et al. MiRNA-210 modulates a nickelinduced cellular energy metabolism shift by repressing the iron-sulfur cluster assembly proteins ISCU1/2 in Neuro2a cells. Cell Death Dis 2014;5:e1090.

44. Tang H, Ayon RJ, Yuan JX. New insights into the pathology of pulmonary hypertension: implication of the miR-210/ISCU1/2/Fe-S axis. EMBO Mol Med 2015;7:689-91.

45. Gou D, Ramchandran R, Peng X, et al. miR-210 has an antiapoptotic effect in pulmonary artery smooth muscle cells during hypoxia. Am J Physiol Lung Cell Mol Physiol 2012;303:L682-91.

46. Zhao L, Oliver E, Maratou K, et al. The zinc transporter ZIP12 regulates the pulmonary vascular response to chronic hypoxia. Nature 2015;524:356-60.

47. Michelakis ED, Reeve HL, Huang JM, et al. Potassium channel diversity in vascular smooth muscle cells. Can J Physiol Pharmacol 1997;75:889-97.

48. Sweeney M, Yu Y, Platoshyn O, et al. Inhibition of endogenous TRP1 decreases capacitative $\mathrm{Ca} 2+$ entry and attenuates pulmonary artery smooth muscle cell proliferation. Am J Physiol Lung Cell Mol Physiol 2002;283:L144-55.

49. Park MK, Lee SH, Ho WK, et al. Redox agents as a link 
between hypoxia and the responses of ionic channels in rabbit pulmonary vascular smooth muscle. Exp Physiol 1995;80:835-42.

50. Brayden JE. Functional roles of KATP channels in vascular smooth muscle. Clin Exp Pharmacol Physiol 2002;29:312-6.

51. Smith KA, Voiriot G, Tang H, et al. Notch Activation of $\mathrm{Ca}(2+)$ Signaling in the Development of Hypoxic Pulmonary Vasoconstriction and Pulmonary Hypertension. Am J Respir Cell Mol Biol 2015;53:355-67.

52. Smith KA, Ayon RJ, Tang H, et al. Calcium-Sensing Receptor Regulates Cytosolic [Ca 2+ ] and Plays a Major Role in the Development of Pulmonary Hypertension. Front Physiol 2016;7:517.

53. Shafik NM, Mohamed DA, Bedder AE, et al. Significance of Tissue Expression and Serum Levels of Angiopoietinlike Protein 4 in Breast Cancer Progression: Link to NF$\kappa \mathrm{B} / \mathrm{P} 65$ Activity and Pro-Inflammatory Cytokines. Asian Pac J Cancer Prev 2015;16:8579-87.

54. Wu SL, Li YJ, Liao K, et al. 2-Methoxyestradiol inhibits the proliferation and migration and reduces the radioresistance of nasopharyngeal carcinoma CNE-2 stem cells via $\mathrm{NF}-\kappa \mathrm{B} / \mathrm{HIF}-1$ signaling pathway inactivation and EMT reversal. Oncol Rep 2017;37:793-802.

55. Han S, Xu W, Wang Z, et al. Crosstalk between the HIF1 and Toll-like receptor/nuclear factor- $\kappa \mathrm{B}$ pathways in the oral squamous cell carcinoma microenvironment. Oncotarget 2016;7:37773-89.

56. Jayaprakash P, Ai M, Liu A, et al. Targeted hypoxia reduction restores $T$ cell infiltration and sensitizes prostate cancer to immunotherapy. J Clin Invest 2018;128:5137-49.

57. Wang JH, Zhao L, Pan X, et al. Hypoxia-stimulated cardiac fibroblast production of IL-6 promotes myocardial fibrosis via the TGF- $\beta 1$ signaling pathway. Lab Invest 2016;96:839-52.

58. Zhou SG, Lei XY, Liao DF. Effects of hypoxic preconditioning on the adhesion of neutrophils to vascular endothelial cells induced by hypoxia/reoxygenation. Zhongguo Wei Zhong Bing Ji Jiu Yi Xue 2003;15:159-62.

59. Liu J, Cai G, Li M, et al. Fibroblast growth factor 21 attenuates hypoxia-induced pulmonary hypertension by upregulating PPAR $\gamma$ expression and suppressing inflammatory cytokine levels. Biochem Biophys Res Commun 2018;504:478-84.

60. Liu Y, Sun Z, Zhu J, et al. LncRNA-TCONS_00034812 in cell proliferation and apoptosis of pulmonary artery smooth muscle cells and its mechanism. J Cell Physiol 2018;233:4801-14.

61. He RL, Wu ZJ, Liu XR, et al. Calcineurin/NFAT
Signaling Modulates Pulmonary Artery Smooth Muscle Cell Proliferation, Migration and Apoptosis in Monocrotaline-Induced Pulmonary Arterial Hypertension Rats. Cell Physiol Biochem 2018;49:172-89.

62. Rahmani M, Nkwocha J, Hawkins E, et al. Cotargeting BCL-2 and PI3K Induces BAX-Dependent Mitochondrial Apoptosis in AML Cells. Cancer Res 2018;78:3075-86.

63. Rybka V, Suzuki YJ, Shults NV. Effects of Bcl-2/Bcl-xL Inhibitors on Pulmonary Artery Smooth Muscle Cells. Antioxidants (Basel) 2018;7:150.

64. Liu Y, Cao Y, Sun S, et al. Transforming growth factorbeta1 upregulation triggers pulmonary artery smooth muscle cell proliferation and apoptosis imbalance in rats with hypoxic pulmonary hypertension via the PTEN/AKT pathways. Int J Biochem Cell Biol 2016;77:141-54.

65. You B, Liu Y, Chen J, et al. Vascular peroxidase 1 mediates hypoxia-induced pulmonary artery smooth muscle cell proliferation, apoptosis resistance and migration. Cardiovasc Res 2018;114:188-99.

66. Del Pozo R, Hernandez Gonzalez I, Escribano-Subias P. The prostacyclin pathway in pulmonary arterial hypertension: a clinical review. Expert Rev Respir Med 2017;11:491-503

67. Lopes AA, Maeda NY, Gonçalves RC, et al. Endothelial cell dysfunction correlates differentially with survival in primary and secondary pulmonary hypertension. Am Heart J 2000;139:618-23.

68. Taraseviciene-Stewart L, Scerbavicius R, Choe KH, et al. Simvastatin causes endothelial cell apoptosis and attenuates severe pulmonary hypertension. Am J Physiol Lung Cell Mol Physiol 2006;291:L668-76.

69. Nishi SP, Zhang W, Kuo YF, et al. Oxygen therapy use in older adults with chronic obstructive pulmonary disease. PLoS One 2015;10:e0120684.

70. Mason RP, Dawoud H, Jacob RF, et al. Eicosapentaenoic acid improves endothelial function and nitric oxide bioavailability in a manner that is enhanced in combination with a statin. Biomed Pharmacother 2018;103:1231-7.

71. Deng JL, Zhang R, Zeng Y, et al. Statins induce cell apoptosis through a modulation of AKT/FOXO1 pathway in prostate cancer cells. Cancer Manag Res 2019;11:7231-42.

72. Wang P, Yang J, Yang Y, et al. Effect of azithromycin in combination with simvastatin in the treatment of chronic obstructive pulmonary disease complicated by pulmonary arterial hypertension. Pak J Med Sci 2017;33:260-4.

73. Zhu S, Wang J, Wang X, et al. Protection against monocrotaline-induced pulmonary arterial hypertension and caveolin-1 downregulation by fluvastatin in rats. Mol 
Med Rep 2018;17:3944-50.

74. Gao C, Fu Y, Li Y, et al. Microsomal Prostaglandin E Synthase-1-Derived PGE2 Inhibits Vascular Smooth Muscle Cell Calcification. Arterioscler Thromb Vasc Biol 2016;36:108-21.

75. Yagami T, Koma H, Yamamoto Y. Pathophysiological Roles of Cyclooxygenases and Prostaglandins in the Central Nervous System. Mol Neurobiol 2016;53:4754-71.

76. Kobayashi K, Omori K, Murata T. Role of prostaglandins in tumor microenvironment. Cancer Metastasis Rev 2018;37:347-54.

77. Reece C, Kumar R, Nienow D, et al. Extending the rationale of combination therapy to unresponsive erectile dysfunction. Rev Urol 2007;9:197-206.

78. Park J, Song JH, Park DA, et al. Systematic review and meta-analysis of pulmonary hypertension specific therapy for exercise capacity in chronic obstructive pulmonary disease. J Korean Med Sci 2013;28:1200-6.

79. Villanueva DLE, Agustin RD, Llanes EJ. Pre-Operative Sildenafil for Patients With Pulmonary Hypertension Undergoing Mitral Valve Surgery: A Systematic Review and Meta-Analysis. Cardiol Res 2019;10:369-77.

80. Vitulo P, Stanziola A, Confalonieri M, et al. Sildenafil in severe pulmonary hypertension associated with chronic obstructive pulmonary disease: A randomized controlled

Cite this article as: Chai T, Qiu C, Xian Z, Lu Y, Zeng Y, $\mathrm{Li}$ J. A narrative review of research advances in hypoxic pulmonary hypertension. Ann Transl Med 2022;10(4):230. doi: 10.21037/atm-22-259 multicenter clinical trial. J Heart Lung Transplant 2017;36:166-74.

81. Zisman D A, Ross DJ, Belperio JA, et al. Prediction of pulmonary hypertension in idiopathic pulmonary fibrosis. Respir Med 2007;10:2153-9.

82. Blanco I, Santos S, Gea J, et al. Sildenafil to improve respiratory rehabilitation outcomes in COPD: a controlled trial. Eur Respir J 2013;42:982-92.

83. Jackson RM, Glassberg MK, Ramos CF, et al. Sildenafil therapy and exercise tolerance in idiopathic pulmonary fibrosis. Lung 2010;188:115-23.

84. Valerio G, Bracciale P, Grazia D'Agostino A. Effect of bosentan upon pulmonary hypertension in chronic obstructive pulmonary disease. Ther Adv Respir Dis 2009;3:15-21.

85. King TE Jr, Brown KK, Raghu G, et al. BUILD-3: a randomized, controlled trial of bosentan in idiopathic pulmonary fibrosis. Am J Respir Crit Care Med 2011;184:92-9.

86. Raghu G, Behr J, Brown KK, et al. Treatment of idiopathic pulmonary fibrosis with ambrisentan: a parallel, randomized trial. Ann Intern Med 2013;158:641-9.

(English Language Editor: J. Jones) 